\title{
Tobacco smoking in seven Latin American cities: the CARMELA study
}

\author{
B M Champagne, ${ }^{1}$ E M Sebrié, ${ }^{2}$ H Schargrodsky, ${ }^{3}$ P Pramparo, ${ }^{4}$ C Boissonnet, ${ }^{5}$ \\ E Wilson ${ }^{6}$
}

${ }^{1}$ InterAmerican Heart

Foundation, Dallas, Texas, USA

${ }^{2}$ Roswell Park Cancer Institute,

Buffalo, New York, USA

${ }^{3}$ Department of Cardiology,

Italian Hospital, Buenos Aires,

Argentina

${ }^{4}$ InterAmerican Heart

Foundation, Buenos Aires,

Argentina

${ }^{5}$ Coronary Care Unit, Centre for Medical Education and Clinical Research "Norberto Quirno", Buenos Aires, Argentina

${ }^{6}$ School of Medicine and Dentistry, University of Rochester, Rochester, New York, USA

\section{Correspondence to}

Ernesto M Sebrié, Roswell Park Cancer Institute, Elm \& Carlton Streets, Buffalo, NY 14263,

USA

ernesto.sebrie@roswellpark.org

Received 3 August 2009 Accepted 27 January 2010 Published Online First 13 August 2010

\section{ABSTRACT}

Objective This study aimed to explore tobacco smoking in seven major cities of Latin America.

Methods The Cardiovascular Risk Factor Multiple Evaluation in Latin America (CARMELA) study is a cross-sectional epidemiological study of 11550 adults between 25 and 64 years old in Barquisimeto, Venezuela; Bogota, Colombia; Buenos Aires, Argentina; Lima, Peru; Mexico City, Mexico; Quito, Ecuador; and Santiago, Chile. Tobacco smoking, including cigarettes, cigars and pipes, was surveyed among other cardiovascular risk factors.

Results Santiago and Buenos Aires had the highest smoking prevalence $(45.4 \%$ and $38.6 \%$, respectively); male and female rates were similar. In other cities, men smoked more than women, most markedly in Quito (49.4\% of men vs $10.5 \%$ of women). Peak male smoking prevalence occurred among the youngest two age groups (25-34 and 35-44 years old). Men and women of Buenos Aires smoked the highest number of cigarettes per day on average (15.7 and 12.4, respectively). Men initiated regular smoking earlier than women in each city (ranges 13.7-20.0 years vs 14.2-21.1 years, respectively). Exposure to secondhand tobacco smoke at workplace for more than $5 \mathrm{~h}$ per day was higher in Barquisimeto (28.7\%), Buenos Aires (26.8\%) and Santiago (21.5\%). The highest prevalence of former smokers was found among men in Buenos Aires, Santiago and Lima (30.0\%, 26.8\% and 26.0\% respectively).

Conclusions Smoking prevalence was high in the seven CARMELA cities, although patterns of smoking varied among cities. A major health and economic burden is inevitable in urban Latin America unless effective comprehensive tobacco control measures recommended by the World Health Organisation Framework Convention on Tobacco Control are implemented.

Many developing countries are experiencing a tobacco epidemic, portending increased burden of chronic diseases. Well known as the main causal factor for lung cancer, tobacco use also promotes the development of vascular disease ${ }^{1}$ and, thus, is a risk factor for ischaemic and peripheral heart disease and stroke. ${ }^{2}$ Smoking is responsible for half of all avoidable deaths worldwide, ${ }^{3}$ and half of those deaths occur during the stage of life that is normally the most productive. ${ }^{4}$ Currently, cardiovascular disease accounts for nearly half of smoking-related deaths in developed nations and more than a quarter in developing regions. ${ }^{5}$ Smoking has been on the rise in developing regions, and by 2030 , it has been estimated that approximately $70 \%$ of the 10 million deaths attributed to tobacco will occur in low- and middle-income countries. $^{4}$

Epidemiological studies have confirmed the contribution of active smoking to cardiovascular risk. In 2004, the INTERHEART Study reported an odds ratio (OR) for acute myocardial infarction of 2.87 for current versus never smokers, ${ }^{6}$ which is similar to another study conducted in Latin America in 1998 that found ORs of 2.50, 2.12 and 2.40 in Venezuela, Mexico and Argentina, respectively. ${ }^{7}$

Exposure to secondhand tobacco smoke (SHS) has been found to increase the risk of cardiovascular disease by approximately $30 \%$, more so than would be expected based on comparable amounts of active exposure to tobacco smoke. ${ }^{8}$ In 2003-2004, high levels of airborne nicotine were found extensively in public places in several Latin American cities, particularly in Argentina and Uruguay. ${ }^{9}$

Despite strong recommendations to eliminate smoking to reduce cardiovascular disease, ${ }^{10}$ the World Health Organisation (WHO) estimates that worldwide, the number of smokers is expected to increase from 1.3 billion to 1.7 billion by the year 2025. ${ }^{11}$

In 2005, the WHO Framework Convention on Tobacco Control (FCTC), the first global public health treaty to adopt evidence-based measures aimed at reducing tobacco consumption, became into force. ${ }^{12}$ While smoking has declined in highincome countries after governmental tobacco control policies were implemented, $82 \%$ of the smokers live in low- and middle-income countries. ${ }^{13}$

In Latin American countries, not enough information has been available for local policymakers to implement tobacco control measures in accordance with specific cultural and economic milieus. ${ }^{4}{ }^{14} \mathrm{We}$ were not able to find in the peer-reviewed literature smoking prevalence studies among adults in Latin America using a standardised and comparable methodology. In 2007, and as a component of the WHO/Centers for Disease Control and Prevention Global Tobacco Surveillance System, the Global Adult Tobacco Survey was launched to systematically collect data on tobacco use among adults comparable across countries. Data from Brazil, Mexico and Uruguay was gathered In Latin America. However, no results have been published as of December 2009. The Cardiovascular Risk Factor Multiple Evaluation in Latin America (CARMELA) Study explored the prevalence of cardiovascular risk factors, including the assessment of smoking and SHS exposure, in seven major cities of Latin America. An initial report from the unlocked scheme, see http// about/unlocked.xhtml 
entire CARMELA Study has previously been published. ${ }^{15}$ The findings related to prevalence and associations of smoking are reported here.

\section{METHODS}

\section{Study design}

CARMELA is a multistage, cross-sectional epidemiological study conducted between September 2003 and August 2005 in Barquisimeto, Venezuela; Bogota, Colombia; Buenos Aires, Argentina; Lima, Peru; Mexico City, Mexico; Quito, Ecuador; and Santiago, Chile. The study was approved by local human research ethics committees in each country.

\section{Sampling}

A total of 11550 participants (approximately 1600 participants per city) between the ages of 25 and 64 years were included, stratified by sex and four 10-year age groups (25-34, 35-44, 45-54 and 55-64). This number was selected on the basis of the sample sizes in similar studies, expected variation in risk factors and limitations dictated by study resources. Cities were first divided into geographic sectors and then into primary sampling units (city blocks or other appropriate areas), which were randomly selected for further sampling. Households present in selected primary sampling units were placed into four categories, and then a systematic sample was obtained within each category. In category 1 , all eligible and consenting residents aged 25-64 years were interviewed; in category 2, only residents aged 35-64 years were interviewed; in category 3 , only residents aged 45-64 years were interviewed; and in category 4, only residents aged 55-64 years were interviewed. The sampling fraction in each category was determined so that an equal probability sampling was obtained within each sex-age group. This strategy was conceived to minimise the number of households to be visited, taking into account that group sizes decrease with age. Sampling was also adjusted on the basis of non-response rates from a pilot study of 50 enrollees per city. Each city resident between the ages of 25 and 64 years (and ultimately everyone in each defined age group) had a predetermined non-zero probability of selection. Anyone within the age limits residing at selected addresses was eligible for inclusion; subjects were included only if they completed the survey and clinical visit. Exclusion criteria comprised persons residing at addresses that were not households or were in marginal areas considered to endanger interviewers and persons visiting at the selected addresses. Interviewers, trained and certified by CARMELA investigators, administered a questionnaire customised from well-known cardiovascular epidemiological questionnaires (WHO STEPwise approach to surveillance and the US Behavioural Risk Factor Surveillance System) to collect information on demographics, hypertension, hypercholesterolemia, diabetes and smoking. More details on the study design are described elsewhere. ${ }^{15}$

\section{Definitions}

Current smokers are those individuals who have smoked 100 cigarettes, 20 cigars or 20 pipes in their lifetime daily or occasionally and who currently smokes cigarettes, cigars or pipes. Former smokers are those who have smoked at least 100 cigarettes, 20 cigars or 20 pipes in their lifetimes but who had not smoked in the past 12 months. Never smokers are those who have never smoked or who have smoked $<100$ cigarettes, 20 cigars or 20 pipes in their lifetime.

\section{Statistical analysis}

Statistical processing addressed the non-equal probability character of the sample and the structure of the design to generate data adjusted for the age and gender distribution of the population of each city. Means and prevalence along with their $95 \%$ confidence intervals were estimated by survey analysis procedures (SAS Software, Release 9.1), taking into account the multistage stratified sampling design via CLUSTER and STRATA statements.

\section{RESULTS}

CARMELA surveyed a total of 11550 participants: 1848 (Barquisimeto), 1553 (Bogota), 1482 (Buenos Aires), 1652 (Lima), 1722 (Mexico City), 1638 (Quito) and 1655 (Santiago).

\section{Demographics}

Table 1 shows demographic characteristics of the sample in each of the seven cities. In this study, participants from Buenos Aires had the highest level of formal education, and those from Barquisimeto had the lowest. In all seven cities, overall, men had higher level of education than women. The age group 25-34 years had the highest level of education in almost all seven cities, and the age group 55-64 years had the lowest.

Table 1 Demographics: education level* (mean) (95\% CI) by city, sex and age group

\begin{tabular}{|c|c|c|c|c|c|c|c|}
\hline & $\begin{array}{l}\text { Barquisimeto } \\
(n=1848)\end{array}$ & $\begin{array}{l}\text { Bogota } \\
(n=1553)\end{array}$ & $\begin{array}{l}\text { Buenos Aires } \\
(n=1482)\end{array}$ & $\begin{array}{l}\text { Lima } \\
(n=1652)\end{array}$ & $\begin{array}{l}\text { Mexico city } \\
(n=1722)\end{array}$ & $\begin{array}{l}\text { Quito } \\
(n=1638)\end{array}$ & $\begin{array}{l}\text { Santiago } \\
(n=1655)\end{array}$ \\
\hline Overall & $9.0(8.6-9.3)$ & $9.2(8.8-9.6)$ & $13.9(13.5-14.2)$ & $12.9(12.7-13.2)$ & $12.1(11.8-12.4)$ & $10.5(9.9-11.1)$ & $11.7(11.3-12.0)$ \\
\hline $\mathrm{M}$ & $9.1(8.7-9.4)$ & $9.5(9.0-10.0)$ & $14.0(13.6-14.4)$ & $13.5(13.2-13.9)$ & $13.1(12.7-13.5)$ & $11.3(10.6-11.9)$ & $12.1(11.7-12.5)$ \\
\hline W & $8.9(8.5-9.3)$ & $8.9(8.5-9.4)$ & $13.8(13.3-14.2)$ & $12.4(12.0-12.7)$ & $11.2(10.9-11.5)$ & $9.7(9.1-10.3)$ & $11.3(10.9-11.6)$ \\
\hline \multicolumn{8}{|c|}{$25-34$ years } \\
\hline $\mathrm{M}$ & $10.0(9.5-10.6)$ & $10.6(9.9-11.3)$ & $14.5(13.9-15.1)$ & $13.6(13.2-14.0)$ & $14.2(13.6-14.8)$ & $12.0(10.9-13.0)$ & $13.0(12.4-13.6)$ \\
\hline W & $10.2(9.6-10.8)$ & $10.3(9.7-10.9)$ & $14.5(14.0-15.0)$ & $13.0(12.5-13.4)$ & $12.7(12.1-13.2)$ & $10.9(10.0-11.8)$ & $12.4(12.0-12.8)$ \\
\hline \multicolumn{8}{|c|}{$35-44$ years } \\
\hline $\mathrm{M}$ & $8.5(7.9-9.2)$ & $9.1(8.5-9.7)$ & $14.2(13.5-14.8)$ & $13.8(13.4-14.3)$ & $12.8(12.3-13.4)$ & $11.7(10.8-12.6)$ & $12.4(11.9-12.9)$ \\
\hline W & $9.0(8.4-9.6)$ & $9.0(8.5-9.6)$ & $14.5(13.8-15.2)$ & $12.4(11.8-13.0)$ & $11.5(11.0-12.0)$ & $10.1(9.2-11.0)$. & $11.5(10.9-12.0)$ \\
\hline \multicolumn{8}{|c|}{$45-54$ years } \\
\hline $\mathrm{M}$ & $8.8(8.2-9.4)$ & $9.3(8.5-10.1)$ & $14.0(13.2-14.8)$ & $13.3(12.7-13.9)$ & $12.0(11.4-12.6)$ & $10.3(9.5-11.1)$ & $11.4(10.9-12.0)$ \\
\hline W & $7.7(7.3-8.2)$ & $8.1(7.4-8.8)$ & $13.9(13.1-14.7)$ & $12.0(11.5-12.5)$ & $10.0(9.4-10.5)$ & $8.4(7.8-9.1)$ & $10.5(10.0-11.1)$ \\
\hline \multicolumn{8}{|c|}{$55-64$ years } \\
\hline $\mathrm{M}$ & $6.9(6.3-7.5)$ & $7.5(6.8-8.2)$ & $12.8(12.2-13.4)$ & $13.2(12.6-13.9)$ & $11.4(10.4-12.4)$ & $9.4(8.4-10.4)$ & $10.3(9.7-10.8)$ \\
\hline W & $6.6(6.0-7.2)$ & $6.0(5.4-6.6)$ & $11.7(11.0-12.5)$ & $11.1(10.6-11.7)$ & $8.2(7.7-8.7)$ & $6.8(6.2-7.4)$ & $9.6(9.0-10.1)$ \\
\hline
\end{tabular}

$95 \% \mathrm{Cl}, 95 \%$ confidence interval.

*Education level as completed years of formal education. 
Table 2 Current smoking* prevalence (\%) (95\% Cl) by city, sex and age group

\begin{tabular}{|c|c|c|c|c|c|c|c|}
\hline & $\begin{array}{l}\text { Barquisimeto } \\
(n=1848)\end{array}$ & $\begin{array}{l}\text { Bogota } \\
(n=1553)\end{array}$ & $\begin{array}{l}\text { Buenos Aires } \\
(n=1482)\end{array}$ & $\begin{array}{l}\text { Lima } \\
(n=1652)\end{array}$ & $\begin{array}{l}\text { Mexico City } \\
(\mathrm{n}=1722)\end{array}$ & $\begin{array}{l}\text { Quito } \\
\text { (n=1638) }\end{array}$ & $\begin{array}{l}\text { Santiago } \\
(n=1655)\end{array}$ \\
\hline Overall & $21.8(19.3-24.2)$ & $22.2(19.1-25.2)$ & $38.6(36.0-41.2)$ & $26.6(23.9-29.4)$ & $27.3(25.0-29.5)$ & $29.9(27.0-32.7)$ & $45.4(42.8-47.9)$ \\
\hline M & $32.2(27.7-36.7)$ & $31.3(27.1-35.5)$ & $39.7(36.2-43.2)$ & $38.0(34.2-41.7)$ & $34.4(30.2-38.5)$ & $49.4(45.9-52.9)$ & $47.7(44.2-51.1)$ \\
\hline \multicolumn{8}{|c|}{$25-34$ years } \\
\hline $\mathrm{M}$ & $39.9(31.1-48.7)$ & $28.4(21.6-35.2)$ & $40.2(33.7-46.7)$ & $40.2(33.8-46.6)$ & $36.7(30.2-43.3)$ & $51.3(44.2-58.4)$ & $50.5(43.5-57.6)$ \\
\hline W & $8.9(5.2-12.6)$ & $13.2(7.4-18.9)$ & $38.8(32.8-44.9)$ & $16.3(10.8-21.9)$ & $20.2(14.5-25.9)$ & $9.5(5.5-13.5)$ & $50.5(43.1-57.9)$ \\
\hline W & $22.9(18.2-27.6)$ & $18.8(12.1-25.4)$ & $39.4(33.5-45.2)$ & $15.7(10.9-20.5)$ & $24.5(19.2-29.9)$ & $12.2(7.1-17.2)$ & $41.7(35.5-47.8)$ \\
\hline \multicolumn{8}{|c|}{ 45-54 years } \\
\hline M & $25.9(18.6-33.3)$ & $27.5(20.1-34.9)$ & $35.5(27.7-43.3)$ & $36.9(30.1-43.7)$ & $29.8(22.2-37.3)$ & $46.5(39.0-54.1)$ & $42.2(35.5-48.8)$ \\
\hline W & $15.3(11.3-19.3)$ & $14.7(9.7-19.6)$ & $41.2(33.2-49.2)$ & $17.4(12.7-22.1)$ & $21.5(17.2-25.8)$ & $12.4(7.9-16.8)$ & $46.0(38.6-53.3)$ \\
\hline \multicolumn{8}{|c|}{ 55-64 years } \\
\hline
\end{tabular}

95\% Cl, 95\% confidence interval.

*Current smoking is defined as daily or occasional smoking of cigarettes, cigars or pipes.

\section{Smoking prevalence}

Table 2 shows current smoking prevalence by city, sex and age group. In this study, overall smoking prevalence ranged from $21.8 \%$ (in Barquisimeto) to $45.4 \%$ (in Santiago) across all seven CARMELA cities. The highest male smoking prevalences were found in Santiago and Quito (47.7\% and $49.4 \%$, respectively), while the highest female smoking prevalences were found in Santiago and Buenos Aires (43.3\% and $37.7 \%$, respectively). Among men, smoking was most frequent in the youngest two age groups (25-34 and 35-44 years old) and declined with successive age groups. Female smoking prevalence was lowest in the oldest age range of each city. Quito had the highest male smoking prevalence and the lowest female smoking prevalence in all age groups studied. Men of Bogota and Lima of all age ranges had approximately twice the smoking prevalence as did women of the same age, while men and women of Buenos Aires and Santiago had similar smoking prevalence.

Table 3 shows the smoking status by city and sex. Never smokers were consistently higher among women than men in all studied cities, with Quito and Santiago having the highest and the lowest never smoking prevalence $(83.9 \%$ and $39.4 \%$ respectively).

\section{Age of smoking initiation}

In our study, smoking initiation occurred among the youngest in Santiago (15.1 years) and the oldest in Mexico City (22.6 years). These data are not consistent with other research studies previously published, and the differences may be the result of the age interval of our sample (25-64 years). Men initiated regular smoking earlier than women of each city (ranges, $13.7-20.0$ vs $14.2-21.1$ years, respectively).

\section{Daily number of cigarettes}

Figure 1 shows the mean daily consumption of cigarettes by sex and city. Of those daily smokers who have smoked within the month before the survey, those in Mexico City smoked the smallest number of cigarettes per day on average (5.5), while those in Buenos Aires smoked the largest (13.9). In all cities, men smoked more cigarettes per day than women, with the largest difference in Barquisimeto and Buenos Aires. In Santiago, a city with relatively high and similar male and female smoking prevalence, a nearly equivalent number of cigarettes were smoked per day (8.0 and 7.9, respectively).

\section{Quit attempts}

In the 12 months before the study, $65.4 \%$ and $52.6 \%$ of smokers in Mexico City and Lima, respectively, tried to quit smoking, while $<40 \%$ of smokers in other cities tried to quit. Of those smokers who ever attempted to quit, mean number of life attempts ranged from 2.5 (Bogotá) to 3.9 (Lima). In all cities, greater numbers of smokers had quit in the last $1-5$ years than within the 5-10 years before the study.

\section{Secondhand tobacco smoke exposure}

Extensive exposure to SHS in the workplace ( $>5 \mathrm{~h}$ /day) was reported by approximately $25 \%$ of participants in Barquisimeto,

Table 3 Smoking status prevalence (\%) (95\% Cl) by city and sex

\begin{tabular}{|c|c|c|c|c|c|c|c|}
\hline & Barquisimeto & Bogota & Buenos Aires & Lima & Mexico city & Quito & Santiago \\
\hline \multicolumn{8}{|l|}{ Men } \\
\hline Current* & $32.2(27.7-36.7)$ & $31.3(27.1-35.5)$ & $39.7(36.2-43.2)$ & $38.0(34.2-41.7)$ & $34.4(30.2-38.5)$ & $49.4(45.9-52.9)$ & $47.7(44.2-51.1)$ \\
\hline Former† & $22.3(19.2-25.3)$ & $18.9(15.2-22.5)$ & $30.0(26.9-33.1)$ & $26.0(22.6-29.4)$ & $14.8(12.1-17.6)$ & $18.0(15.5-20.5)$ & $26.8(23.6-30.1)$ \\
\hline \multicolumn{8}{|l|}{ Women } \\
\hline Current* & $14.9(12.7-17.1)$ & $15.0(11.1-18.9)$ & $37.7(34.2-41.3)$ & $15.4(12.6-18.2)$ & $21.0(18.8-23.2)$ & $10.5(7.8-13.2)$ & $43.3(39.7-46.9)$ \\
\hline Former† & $12.8(10.9-14.7)$ & $8.5(6.4-10.7)$ & $23.1(18.0-24.5)$ & $21.8(18.4-25.2)$ & $8.9(6.7-11.1)$ & $5.6(3.7-7.6)$ & $17.3(14.9-19.8)$ \\
\hline
\end{tabular}

$95 \% \mathrm{Cl}, 95 \%$ confidence interval.

* Participants who reported daily or occasional consumption of cigarettes, cigars or pipe tobacco.

†Participants who had smoked at least 100 cigarettes, 10 cigars or 10 pipes in their lifetime but who have quit smoking a year ago.

$\ddagger$ Participants who never smoked or smoked $<100$ cigarettes, 20 cigars or 20 pipes in their lifetime. 


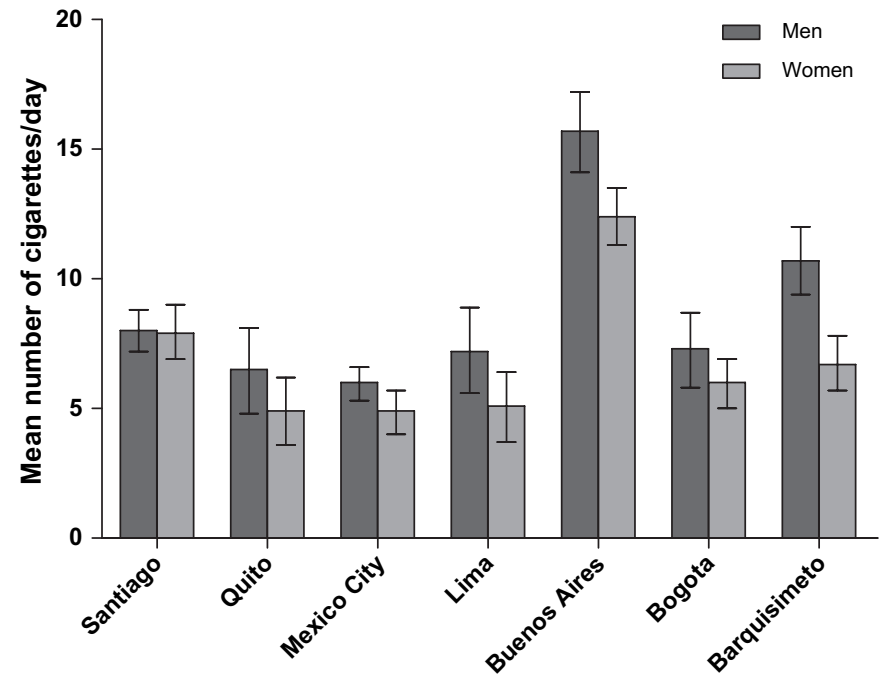

Figure 1 Mean (95\% Cl) daily consumption of cigarettes by sex and city in participants who smoked within the month before survey.

Buenos Aires and Santiago, but was much less common in Bogota, Lima, Mexico City and Quito (8.6\%, 5.0\%, 14.5\% and $3.9 \%$, respectively). Among participants living with at least one smoker, Quito and Santiago had the highest percentage reporting that smoking was not allowed at home $(43.3 \%$ and $44.9 \%$, respectively), while Barquisimeto and Buenos Aires had the lowest (13.4\% and $13.5 \%$, respectively).

\section{DISCUSSION}

The CARMELA Study revealed large differences in smoking prevalence in urban Latin America. In this study, the highest overall smoking prevalences were found in Buenos Aires and Santiago with no gender differences. In contrast, in all other cities, smoking prevalence in men was higher than in women, reaching in Quito nearly five times more. Peak smoking prevalence was found among younger participants. Men initiated smoking at earlier ages than women. Smokers in Buenos Aires smoked the most number of cigarettes per day, and in all cities except Santiago, men smoked more cigarettes than women per day. Participants reported a high exposure to SHS both at work and at home.

It has been estimated that worldwide, $29 \%$ of the population aged 15 years and older smoke tobacco, with highest overall rates in Europe and Central Asia (35\%). Globally, men smoke more than women ( $47 \%$ vs $11 \%$, respectively), and prevalence of daily smoking peaks at ages $30-49$ years $(36-37 \%) .{ }^{13}$ Although variable by country, adult smoking prevalence in Latin America has been reported to be approximately $40 \%$ for men and $24 \%$ for women, with $32 \%$ prevalence overall. ${ }^{4}$ A 2008 WHO report published adjusted prevalence estimates that are lower than previously reported. ${ }^{16}$ The results of the CARMELA Study bear out these estimates. In general, men smoked more than women, and in total, $30.2 \%$ of CARMELA Study participants reported current smoking. Overall number of cigarettes consumed daily on average in CARMELA cities was relatively low, except in Buenos Aires. Although age-group overlap might preclude adequate comparisons, the highest smoking prevalence in all CARMELA cities was found in younger age groups than worldwide estimates suggest.

Between 1989 and 1992, various studies show that 35-41\% of men and $13-19 \%$ of women of Peru, Argentina, Mexico, Chile and Colombia were smokers. ${ }^{17}$ Over a decade later, the CARMELA Study seems to indicate that more women are smoking in Lima, Buenos Aires, Mexico City and Santiago, markedly so in Santiago and Buenos Aires, cities that now have similar prevalence in both genders. One possible explanation for the apparent increase in tobacco consumption among women would be the tobacco companies' marketing strategies targeting young women. ${ }^{18}$ However, caution is necessary in comparing these results, given the entirely urban population of CARMELA and the cross-sectional nature of both studies. More recently, WHO reported a higher smoking prevalence among women of Venezuela, Colombia, Mexico and Ecuador and a lower prevalence of both genders in Chile than in corresponding CARMELA cities. ${ }^{16}$ Nonetheless, the WHO data generally include younger participants (lower limit, 15-18 years of age) and have less standardised methods than the CARMELA Study. Both results from the CARMELA Study and WHO may underestimate true smoking prevalence, as data collected were self-reported and lacked objective validation with, for example, urine cotinine levels. ${ }^{19}$

The stages of the tobacco epidemic model described by Lopez et $a l^{3}$ may be used to describe differences among CARMELA cities. This model was developed as a descriptive tool for Western developed countries and, as such, may not be entirely applicable to Latin America. Furthermore, whether the lung cancer epidemic is as consistently reflective for women has been questioned recently. ${ }^{20}$ Nevertheless, with the additional caveat that CARMELA is a cross-sectional study carried out over a relatively short time span, the model might provide a context with which to inform national and local health initiatives.

Buenos Aires, with its high smoking prevalence for men and women and the highest daily cigarette use, may be in stage III of the Lopez model. The relatively high tobacco consumption in Buenos Aires, Argentina, a country with the highest gross domestic product per capita of the CARMELA countries, is consistent with trends towards increased consumption with increased disposable income. ${ }^{4}$ This also may be a reflection of cultural differences among Buenos Aires (with a majority of the population of European descendent) and the rest of the participating cities. Nearly half of Santiago adults reported smoking, and although it has a relatively low prevalence of smokers who have attempted to quit $(<40 \%)$, Santiago might be considered early in stage III, with smoking prevalence to decline in the years ahead. Mexico City's smoking prevalence fits within stage II of the model, despite its high rate of smokers who have attempted to quit and relatively low number of cigarettes smoked per day. Barquisimeto, Bogota and Lima have approximately twice as many male smokers as female. Lung cancer mortality in Venezuela and Colombia has been low but generally rising since 1970 for both genders. ${ }^{21}$ All three cities might be considered in Lopez stage II. Quito, with its fivefold difference between male and female prevalence, conforms to stage II of the epidemic albeit at an earlier point than the other cities. The relatively low consumption among the women of Quito might reflect Ecuador's low gross domestic product per capita compared to other CARMELA cities. Another plausible explanation to take into consideration is the difference in cultural factors across cities. In Ecuador, as well as other Andean countries like Peru, there are a considerable percentage of indigenous population (non-European descendent) reflecting cultural differences in patters of tobacco consumption. The classification of most of the CARMELA cities as stage II agrees with the classification of other areas of Latin America. ${ }^{17}$ With relatively high prevalence and unchecked increases in smoking in some Latin American countries, the costs of tobacco-related illnesses are likely to become a substantial economic burden. 
The high smoking prevalence found in CARMELA cities, along with patterns that suggest a growing tobacco epidemic, is alarming not only for its impending impact on cardiovascular disease but also for its augury of extensive morbidity and mortality from other diseases, ${ }^{522} 23$ That most CARMELA cities appear to be in stage II of the Lopez descriptive model does not necessarily mean increased morbidity and mortality in the future as the model predicts. Morbidity from cardiovascular disease decreases quickly after smoking cessation. After a year of abstinence, excess mortality from smoking decreases by half, ${ }^{24}$ and by $3-5$ years after cessation, risk of cardiovascular disease in exsmokers is reduced to that of non-smokers ${ }^{25}$ However, the data from the CARMELA Study indicates that few smokers have tried to quit, and overall, the number of quit attempts was limited.

Likewise, the prevalence of high levels of SHS exposure at home and in workplaces demonstrated in the CARMELA Study presents great challenge to local policymakers. As of December 22, 2009, all Latin American countries except Argentina, Cuba, Dominican Republic and El Salvador (15 out of 19) have ratified the WHO FCTC, ${ }^{12}$ committing themselves to implement the most costeffective tobacco control policies to reduce tobacco consumption and its health consequences. Following WHO recommendations, four countries in the region implemented $100 \%$ smoke-free policies at the national level (Uruguay in 2006, Panama and Colombia in 2008 and Guatemala in 2009). Argentina, Mexico and Brazil have done so at the subnational level. Between 2002 and 2009, six Latin American countries adopted pictorial-based health warning labels on cigarette packages (Brazil, Uruguay, Chile, Venezuela, Panama and Peru), and others are considering to follow suit soon (Mexico, Bolivia and Paraguay). In 2008, Panama became the first country to completely ban tobacco product advertising, sponsorship and promotion.

\section{CONCLUSIONS}

A recurring theme in regional tobacco control efforts is the lack of standardised data on local smoking prevalence and consumption patterns and behaviours. ${ }^{14}$ Using a standardised methodology, the CARMELA Study reports high smoking prevalence in the seven studied cities. Male smoking prevalence ranged between that of developed and developing regions. Female smoking prevalence was higher than previous worldwide estimates. The highest smoking prevalence was among the youngest two age groups, and age of initiation occurs mostly

\section{What is already known on this subject}

Smoking prevalence studies are a key component as part of a surveillance system to evaluate the impact of tobacco control policies. A number of adult smoking prevalence studies have been conducted in Latin America using different methodologies that do not allow making comparisons across countries and monitoring trends within specific countries.

\section{What does this study add}

This is the first study conducted in Latin America on adult smoking prevalence using a standardised and comparable methodology in seven significant urban centres of the region. during adolescence. In addition, substantial SHS exposure was reported both at home and in the workplace. As a result, Latin American urban populations will bear increasing burdens of tobacco-induced chronic diseases. Data from the CARMELA Study should be used wisely and vigorously to develop and endorse effective local tobacco control policies guided by WHO FCTC recommendations.

\section{Limitations}

Some limitations of the CARMELA study include the epidemiological design (eg, cross-sectional) and the age interval of the sample selection (eg, 25-64 years old).

Acknowledgements The authors thank Fabio Pellegrini and Alejandro Macchia of the Consorzio Mario Negri Sud, Chieti, Italy, for their invaluable help in data review, analysis and interpretation; Luis Carlos Silva Ayçaguer of the Centro Nacional de Información de Ciencias Médicas, La Habana, Cuba, for expert sample design; and Javier Valenzuela of the InterAmerican Heart Foundation, Dallas, Texas, USA, for his administrative and communications assistance.

Funding The CARMELA study was funded by an unrestricted research grant from Pfizer, Inc. to the InterAmerican Heart Foundation, a non-profit, tax-exempt organisation as a cooperative and innovative effort between a heart foundation dedicated to heart health (IAHF), a medical society dedicated to the control of hypertension (LASH), and a private sector organisation (Pfizer, Inc.). Dr Sebrié was supported by the Flight Attendant Medical Research Institute (FAMRI).

\section{Competing interests None.}

Ethics approval This study was conducted with the approval of the local human research ethics committees in each country.

Contributors CARMELA Study Committee Members and Investigators Steering committee: Elinor Wilson (Chair); Herman E. Schargrodsky, Rafael Hernández-Hernández, Beatriz Marcet Champagne and Honorio Silva. Scientific committee: Herman E. Schargrodsky (Chair); Francisco Benítez, Ximena Berríos-Carrasola, Carlos Pablo Boissonnet, Jorge Escobedo, Raúl Gamboa-Aboado, Alvaro Ruiz-Morales, Palmira Pramparo, Manuel Velasco and Raúl Vinueza. Participating institutions, coordinators and investigators: Asociación Cardiovascular Centro Occidental: Lic. Elizabeth Infante, Luis Rocha; Pontificia Universidad Javeriana de Bogota: Álvaro Ruíz Morales, Esperanza Peña and Felipe Uriza; Centro de Educación Medica e Investigaciones Clinicas "Norberto Quirno": Carlos Pablo Boissonnet, Juan Fuselli and Víctor Torres; Universidad Cayetano Heredia: Raúl Gamboa-Aboado, Carlos Kiyán and Mario Vargas; Instituto Mexicano de Seguridad Social: Jorge Escobedo, Luisa Buitrón and Jesús Ramírez-Martínez; Hospital Metropolitano de Quito: Francisco Benítez, María Velasco and Luis Falcóni; Pontificia Universidad Católica de Santiago de Chile: Ximena Berrios-Carrasola, Beatriz Guzmán and Mónica Acevedo.

Provenance and peer review Not commissioned; externally peer reviewed.

\section{REFERENCES}

1. Mahonen MS, McElduff P, Dobson AJ, et al. Current smoking and the risk of nonfatal myocardial infarction in the WHO MONICA Project populations. Tob Control 2004;13:244-50.

2. Faxon DP, Creager MA, Smith SC Jr, et al. Atherosclerotic vascular disease conference: executive summary: atherosclerotic vascular disease conference proceeding for healthcare professionals from a special writing group of the American Heart Association. Circulation 2004;109:2595-604.

3. Lopez AD, Collishaw NE, Piha T. A descriptive model of the cigarette epidemic in developed countries. Tob Control 1994:3:242-7.

4. Jha P, Chaloupka FJ, Corrao M, et al. Reducing the burden of smoking world-wide: effectiveness of interventions and their coverage. Drug Alcohol Rev 2006; 25:597-609.

5. Ezzati M, Lopez AD. Regional, disease specific patterns of smoking-attributable mortality in 2000. Tob Control 2004;13:388-95.

6. Yusuf S, Hawken S, Ounpuu S, et al. Effect of potentially modifiable risk factors associated with myocardial infarction in 52 countries (the INTERHEART study) case-control study. Lancet 2004;364:937-52.

7. Ciruzzi M, Schargrodsky H, Pramparo P, et al. Attributable risks for acute myocardia infarction in four countries of Latin America. Medicina 2003;63:697-703.

8. Barnoya J, Glantz SA. Cardiovascular effects of secondhand smoke: nearly as large as smoking. Circulation 2005;111:2684-98.

9. Navas-Acien A, Peruga A, Breysse P, et al. Secondhand tobacco smoke in public places in Latin America, 2002-2003. JAMA 2004;291:2741-5.

10. Pyorala K, De Backer G, Graham I, et al. Prevention of coronary heart disease in clinical practice. Recommendations of the Task Force of the European Society of Cardiology, European Atherosclerosis Society and European Society of Hypertension. Eur Heart J 1994;15:1300-31. 
11. Guindon G, Boisclair D. Past, current and future trends in tobacco use. WHOMorld Bank, Washington DC. HNP Discussion Paper Economics of Tobacco Control, paper no 6. 2003.

12. World Health Organization. Framework convention on tobacco control. Geneva: WHO, 2003

13. Anderson P. Global use of alcohol, drugs and tobacco. Drug Alcohol Rev 2006;25:489-502.

14. Baris $\mathbf{E}$, Brigden LW, Prindiville J, et al. Research priorities for tobacco control in developing countries: a regional approach to a global consultative process. Tob Control 2000;9:217-23.

15. Schargrodsky H, Hernandez-Hernandez R, Champagne BM, et al. CARMELA assessment of cardiovascular risk in seven Latin American cities. Am J Med 2008;121:58-65.

16. World Health Organization. WHO Report on the Global Tobacco Epidemic, 2008: The MPOWER package. Geneva: WHO, 2008.

17. da Costa e Silva VL, Koifman S. Smoking in Latin America: a major public health problem. Cad Saude Publica 1998;14(Suppl 3):99-108.
18. Greaves L. Sifting the evidence: gender and tobacco control. Geneva: WHO/IDRC, 2007.

19. Man CN, Fathelrahman Al, Harn GL, et al. Correlation between urinary nicotine cotinine and self-reported smoking status among educated young adults. Environ Toxicol Pharmacol 2009;28:92-6.

20. Didkowska J, Manczuk M, McNeill A, et al. Lung cancer mortality at ages 35-54 in the European Union: ecological study of evolving tobacco epidemics. BMJ 2005;331(7510):189-91.

21. Bosetti C, Malvezzi M, Chatenoud L, et al. Trends in cancer mortality in the Americas, 1970-2000. Ann Oncol 2005;16:489-511.

22. Thomson NC. The role of environmental tobacco smoke in the origins and progression of asthma. Curr Allergy Asthma Rep 2007;7:303-9.

23. Menezes AM, Perez-Padilla R, Jardim JR, et al. Chronic obstructive pulmonary disease in five Latin American cities (the PLATINO study): a prevalence study. Lancet 2005;366:1875-81.

24. Edwards R. The problem of tobacco smoking. BMJ 2004;328:217-19.

25. Reid RD, Quinlan B, Riley DL, et al. Smoking cessation: lessons learned from clinical trial evidence. Curr Opin Cardiol 2007;22:280-5. 